\title{
The Building Blocks of User-Focused 3D City Models $\dagger, \ddagger$
}

\author{
Isabel Sargent *, David Holland ${ }^{\S}$ and Jenny Harding ${ }^{\S}$ \\ Ordnance Survey, Adanac Drive, Southampton SO16 0AS, UK; \\ E-Mails: david.holland@os.uk (D.H.); jenny.harding@os.uk (J.H.) \\ $\dagger$ This paper is an extended version of our paper published in EuroSDR/ISPRS workshop: "Efficient \\ capturing of 3D objects at a national level".
}

$\ddagger$ This article has been prepared for information purposes only. It is not designed to constitute definitive advice on the topics covered and any reliance placed on the contents of this article is at the sole risk of the reader.

$\S$ These authors contributed equally to this work.

* Author to whom correspondence should be addressed; E-Mail: isabel.sargent@os.uk; Tel.: +44-23-8005-5779.

Academic Editors: Jantien Stoter, Franz Rottensteiner, Fabio Remondino, Norbert Pfeifer and WolfgangKainz

Received: 27 August 2015 / Accepted: 7 November 2015 / Published: 21 December 2015

\begin{abstract}
At Ordnance Survey, GB, we have taken an incremental approach to creating our 3D geospatial database. Research at Ordnance Survey has focused not only on methods for deriving 3D data, but also on the needs of the user in terms of the actual tasks they perform. This provides insights into the type and quality of the data required and how its quality is conveyed. In 2007, using task analysis and user-centred design, we derived a set of geometric characteristics of building exteriors that are relevant to one or more use contexts. This work has been valuable for guiding which building data to collect and how to augment our products. In 2014, we began to supply building height attributes as an alpha-release enhancement to our 2D topography data, OS MasterMap ${ }^{\circledR}$ Topography Layer. This is the first in a series of enhancements of our 2D data that forms part of a road map that will ultimately lead to a full range of 3D products. This paper outlines our research journey from the understanding of the key 3D building characteristics to the development of geo-spatial products and the specification of research. There remains a rich seam of research into
\end{abstract}


methods for capturing user-focused, geo-spatial data to enable visualisation and analysis in three dimensions. Because the process of informing and designing a product is necessarily focused on the practicalities of production, storage and distribution, this paper is presented as a case report, as we believe our journey will be of interest to others involved in the capture of $3 \mathrm{D}$ buildings at a national level.

Keywords: 3D city modelling; building heights; user-centred design

\section{Introduction}

Research at Ordnance Survey, Britain's mapping agency, has long maintained a focus on understanding the tasks undertaken by potential users of spatial data in order to improve the usability of our products $[1,2]$. A decade ago, when investigating tools and methods of $3 \mathrm{D}$ data capture, we needed to assess how well the resulting 3D data met the expected needs of the customer. In particular, we were concerned with the geometric accuracy of 3D building data, as this was the focus of our data capture research. There has been some detailed work into developing methods for assessing the geometric accuracy of 3D models, [3,4] and more recently [5-7]. Users' tasks are considered when designing tools for interacting with 3D geospatial information [8] and the real-world features that are required by different tasks [9]. None of these works incorporated knowledge about the data users' tasks, so that the quality assessment prioritised those aspects of the data that are key to a given task.

In the absence of much insight into real customer needs (as remains the case $[10,11]$ ), the research department at Ordnance Survey used user-centred design methods to better understand the tasks performed by potential users of spatial data. User-centred design provides a range of tools to ensure attention to user needs and usability throughout the development of products (see, for example, [12]). Specifically, our research elicited detail about a range of tasks by performing a series of task-focused interviews, the results of which could then be interrogated to draw out deeper understanding of the user perspective. Using the output from this process (see [13] for details of our method), our work [13] identified eight key geometric characteristics of 3D buildings that had value for one or more user tasks. These eight characteristics are listed in Table 1. Descriptions of each characteristic, the tasks to which they apply and the accuracy at which they would be required are given in the original paper.

The original intent of this work was to inform the development of user-focused measures of quality for full 3D building models. However, commercial and resource pressures changed the focus of this work over the following decade towards methods for rapidly creating products. Over this time, the number of 3D city models has increased [14], as have the tools available for capturing those data [15] and the maturity of data models [10]. We can expect that the ranges of uses of 3D building data have expanded since our earlier work and that users are increasingly sophisticated. Therefore, it is likely that the user tasks on which the eight characteristics were based are somewhat out-of-date. However, whilst work has continued on measuring the geometric quality of building data using the eight characteristics as a guide, the "characteristics" work has proven more valuable for developing the 3D product that Ordnance Survey offers. In this paper, we discuss how our understanding of the original eight characteristics has developed 
and how this understanding has been incorporated in the design of our products and the specification of research.

Table 1. The 8 characteristics of 3D building data that were identified as important to users.

\begin{tabular}{lll}
\hline ID & Characteristic & Brief Description \\
\hline 1 & Inter-building geometric shape & The 3D shape of the space between the buildings. \\
\hline 2 & Roof geometric shape & The 3D shape of the building's roof. \\
\hline 3 & $\begin{array}{l}\text { Complete building } \\
\text { geometric shape }\end{array}$ & The 3D shape of the whole building. \\
\hline 4 & $\begin{array}{l}\text { Position and dimensions of } \\
\text { doors and windows }\end{array}$ & $\begin{array}{l}\text { Where the windows and doors are located in the building } \\
\text { and their 3D shape. }\end{array}$ \\
\hline 5 & $\begin{array}{l}\text { Highest point of structure } \\
\text { The very highest point on the building (including roof } \\
\text { fixtures, such as chimneys and aerials). }\end{array}$ \\
\hline 7 & $\begin{array}{l}\text { Maximum height of roof ridge } \\
\text { roof (eave height) }\end{array}$ & $\begin{array}{l}\text { The maximum height of the ridge of the roof. This has } \\
\text { been broadened to the maximum height of the main roof } \\
\text { of the building. }\end{array}$ \\
\hline 8 & Ground floor height & $\begin{array}{l}\text { The height from the ground to the bottom of the roof } \\
\text { structure (which is often slightly above the height of } \\
\text { the eave). }\end{array}$ \\
\hline
\end{tabular}

\section{Research and Development of User-Focused 3D Data}

Here, we discuss the original eight characteristics of 3D building models. We expand on the original paper by showing how our understanding and research has developed and how products have been designed, following the original work. The list of characteristics has needed some updates since its original publication. This is largely because neither the user-focused interview techniques nor the analysis for the 2007 paper were intended to identify the specific requirements for a 3D product (they were undertaken to inform the development of methods of quality assessment). Additionally, while the "desk-based" studies of the user interviews and their interrogation proved immensely informative, practical experience with creating and using 3D data, both on our own and our customers' part (e.g., through OS Insight; see [16]), has highlighted several key aspects of 3D data not addressed by the eight characteristics. Nonetheless, we have drawn great value from the exercise of extracting the eight characteristics by extending their application beyond their original purpose of designing quality measures.

For the purpose of this paper, it is logical to address the characteristics grouped by the type of geometry that they suggest: building height data (Section 2.1), three-dimensional shape (Section 2.2) and attribution related to building geometry (Section 2.3). 


\subsection{Building Height Data}

In the original work, four characteristics of 3D buildings were identified that pertained to the heights of features on a building (Figure 1). When considering the design of 3D products, this work suggested an interim solution to providing 3D data: to instead supply a set of single heights for each building in our 2D topographic data. This section demonstrates how these four characteristics were developed into the five building height attributes that are now being captured, as well as two further height attributes that we are currently not capturing.

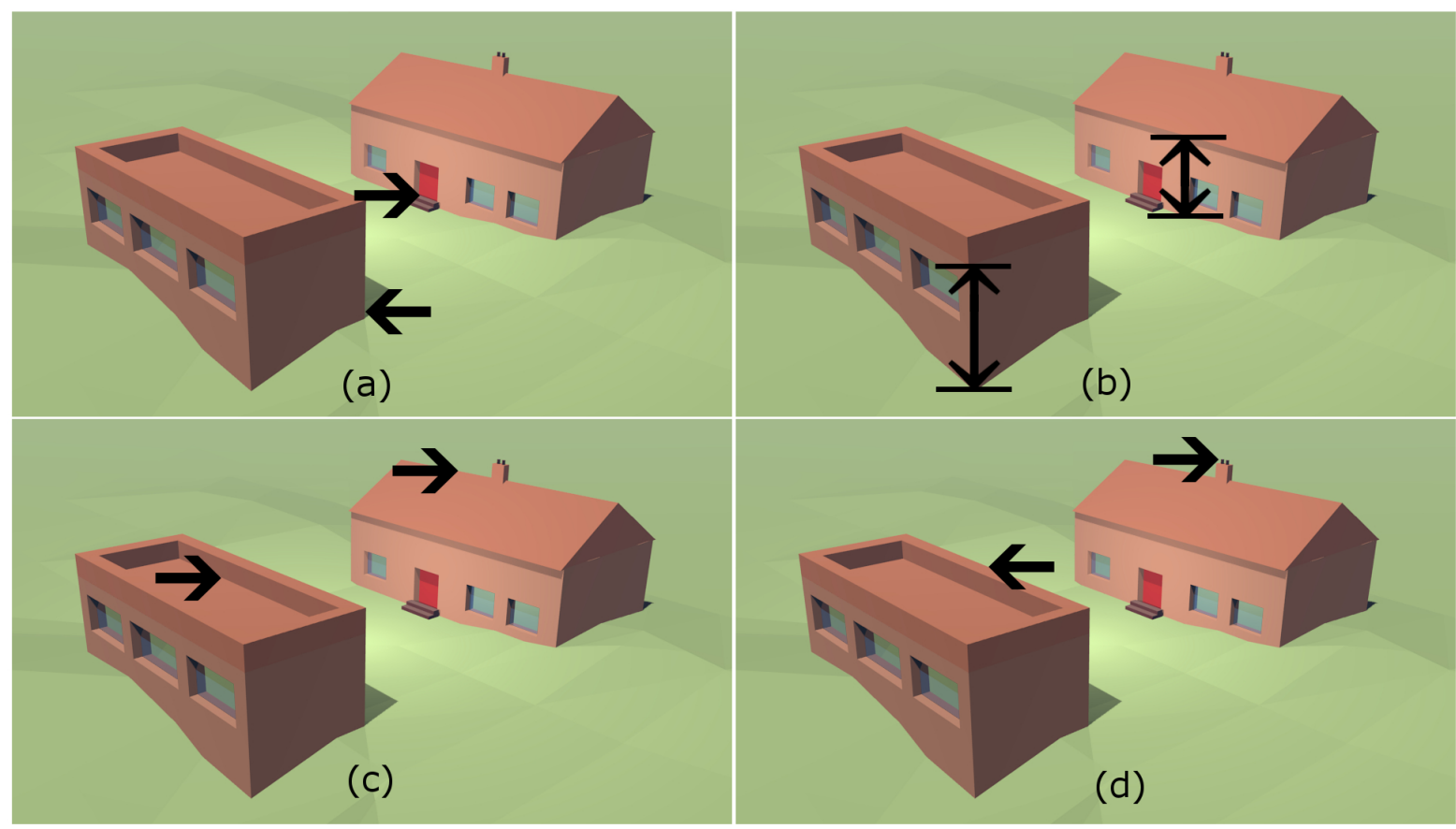

Figure 1. This figure uses synthetic 3D building models for illustrations of the building height characteristics of 3D buildings. (a) Characteristic 8: ground floor height; (b) Characteristic 7: height of building to base of roof; (c) Characteristic 6: maximum height of roof ridge; (d) Characteristic 5: highest point of the structure.

Characteristic 8 represents the height of the floor at ground level ("ground floor height") of a building and is useful for urban design and planning, as well as flood risk assessment. Since this height can only be measured inside a building, which would be prohibitively expensive, we translated this height to the "absolute minimum height of the intersection of the external building walls and the underlying ground surface" (AbsHmin; Figure 2) and are now capturing this height attribute for buildings.

As well as buildings and structures that do intersect the ground, Ordnance Survey records the edges of buildings and structures that are "non-obstructing" or overhead, such as canopies, cantilevered buildings, balconies, overhanging roofs and buildings supported on pillars. The distinction between this and the "ground floor height" was not identified in the 3D building characteristics, an omission that only became apparent with practical experience of representing the real-world as geographic information. Further, we do not currently capture below-ground features, but there is a clear case for the height of the bottom of a building's basement (as identified in both INSPIRE [17] and CityGML [18]) and in user interviews 
concerning emergency response, for example. Therefore, the "height of the base of the building" could be considered as a ninth characteristic. A field in the building height attributes called the "absolute height of the base of the building" (AbsH1; Figure 3) was created to accommodate this attribute. However, the capture of this height will require a data source other than nadir imagery, our current source of data, for those cases where the bottom of the building is not coincident with the terrain. It would not be cost-effective to acquire another data source just to capture this building height, and so, currently, this field is not being populated.

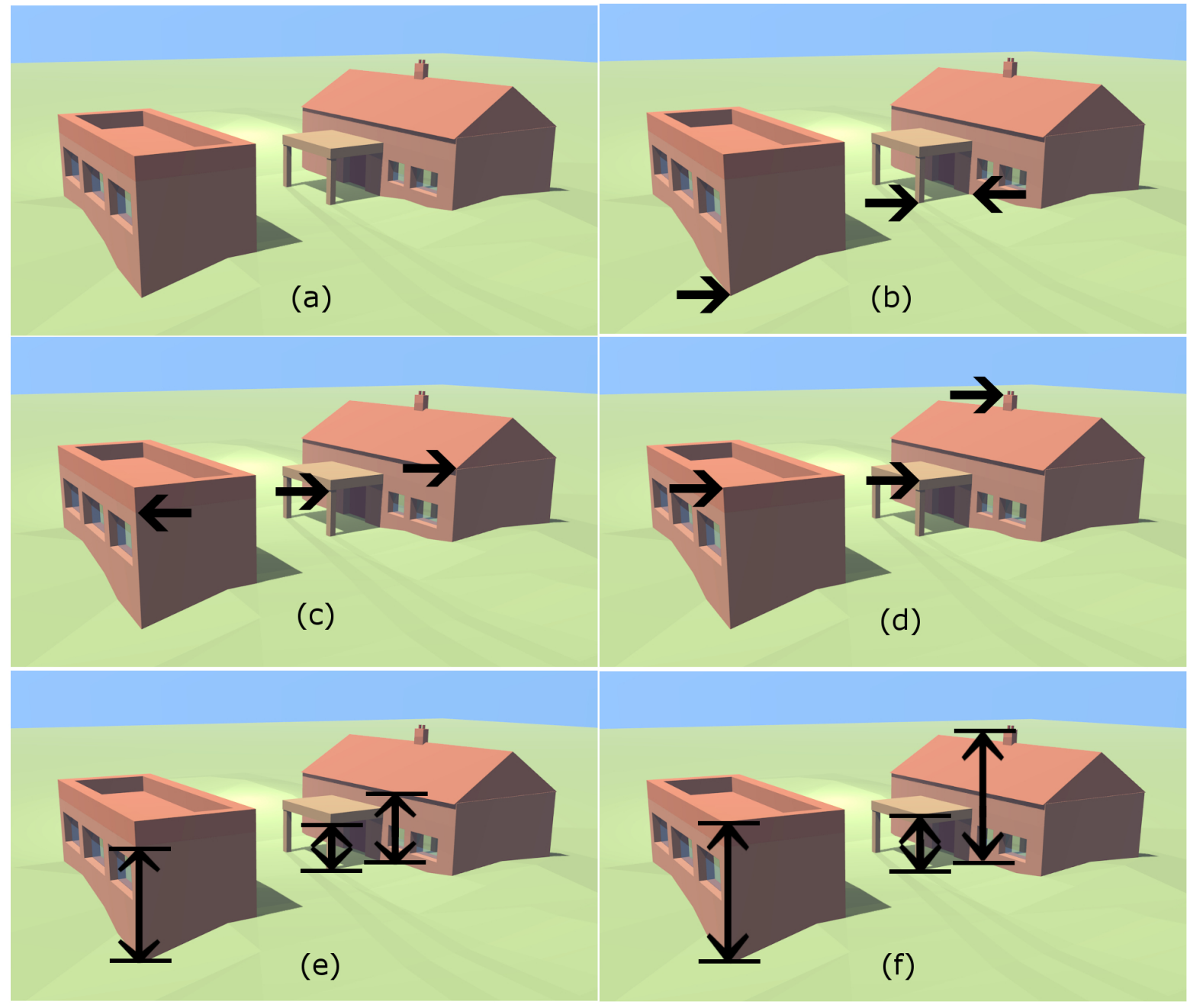

Figure 2. This figure uses synthetic 3D building data to illustrate the building height attributes that are currently being provided as part of the OS MasterMap Topography Layer product. (a) Within our data, Ordnance Survey distinguishes between structures that sit on the ground and those that are "non-obstructing" detail. The following attributes are illustrated for three types of building: a flat-roofed building with a balustrade, a ridge-roofed building with a chimney and an overhead canopy (in this case, connected to the ridge-roofed building). (b) AbsHmin: the absolute minimum height of the intersection of the external building walls and the underlying ground surface; (c) AbsH2: the absolute height of the base of the roof; (d) AbsHmax: the absolute height of the highest point on the building; (e) RelH2: AbsH2 - AbsHmin; (f) RelHmax: AbsHmax - AbsHmin 
Characteristic 7, the "height of the building to base of roof", is important for visualisation for urban design and planning and emergency service incident planning, for example. It is being calculated as the height from the ground (rather than the base of the building) to the base of the roof (RelH2; Figure 2). This requires the capture of the "absolute height of the base of the roof", and so, this is also being stored (as AbsH2; Figure 2), which will give customers options for creating "flat-roofed" 3D block models by extruding the 2D topographic data.
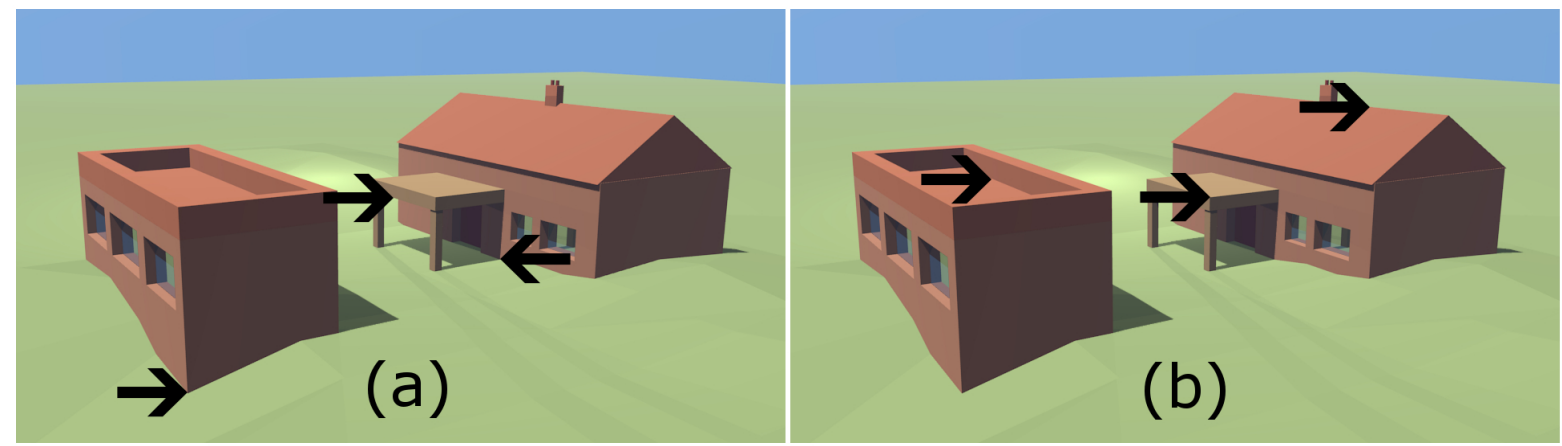

Figure 3. Illustrations of the building height attributes that are not currently available (a) AbsH1: the absolute height of the base of the building; (b) AbsH3: the absolute maximum height of the main roof.

The task analysis was originally quite specific about requiring information about the roof ridge, including its direction (incorporated into Characteristic 2) and height. However, not all buildings have ridges, and therefore, we have broadened the definition of Characteristic 6 to the "absolute maximum height of main roof", in building height attributes (AbsH3; Figure 3). Research into automatically capturing this value is in very early stages, but we hope to be able to populate this height attribute in the future.

The "highest point of structure", Characteristic 5, is being captured as the "absolute height of the highest point on the building" (AbsHmax; Figure 2). Due to the automatic processes being employed to capture this value, the value for AbsHmax does not represent the height of any object on the roof with a footprint of less than about $50 \mathrm{~cm}^{2}$.

The foundation for any $3 \mathrm{D}$ city model is a model of the geometry of the underlying terrain surface. In 2013, Ordnance Survey released a new family of terrain products, OS Terrain [19,20], which currently comprises a five-metre digital terrain model (DTM), OS Terrain 5, and a 50-metre grid spacing DTM, OS Terrain 50, both derived using digital photogrammetry. In 2014, we began to release building height attributes [21] with our 2D topography data, OS MasterMap Topography Layer [22]. This was the culmination of several years of research and development into robust methods for populating the national dataset with data about the height of objects. Within the alpha-release data, each building footprint polygon in the topographic data is attributed with a set of height values. Currently, three absolute height (absolute height is the height above mean sea level, Ordnance Datum Newlyn) values and two relative height values are calculated providing: (1) the absolute minimum height of the intersection of the external building walls and the underlying ground surface (AbsHmin); (2) the absolute height of the base of the 
roof (AbsH2); (3) the absolute height of the highest point on the building (AbsHmax); (4) AbsH2 AbsHmin (RelH2); and (5) AbsHmax - AbsHmin (RelHmax) (Figure 2b-f).

The building height data are calculated using summary statistics from a digital surface model (DSM) that has been automatically derived from aerial photography. The process was a development of [23], creating a more efficient production process, but with increased accuracy of the values.

Feedback from users has been positive. Informally, several have expressed that the building height attributes make new analyses possible, such as building energy modelling and wind modelling in built environments, as well as the expected visualisation of the urban environment for development and planning. The feedback provided at the end of our initial data trial (using OS Insight [16]) found that users considered building height data to be valuable. Yet, there is room for improvement. For instance, $\mathrm{AbsH} 2$, the absolute height of the base of the roof, has been found to be less accurate than the other heights when compared to heights captured using a manual photogrammetric method. This is because the current method of calculating this height (by averaging the heights in the roof DSM) is robust, but does not account for the varying shapes and styles of roof. The AbsHmin height currently does not always intersect with our terrain model, but this is being remedied by developing our terrain model to harmonise with the DSM. We also believe that adding a further height, AbsH3, the "absolute maximum height of the main roof", would overcome reported confusion over the meaning of AbsHmax ("absolute height of the highest point on the building").

Table 2 shows how the OS MasterMap Topography Layer building height attributes relate to the four building height characteristics. INSPIRE Elevation References Values [17] are included for reference.

Table 2. Comparison of building height attributes, as available with the OS MasterMap Topography Layer, and the building height characteristics. INSPIRE Elevation Reference Values are included for reference.

\begin{tabular}{|c|c|c|c|}
\hline Building Characteristic & $\begin{array}{l}\text { Resulting Building } \\
\text { Height Attribute (BHA) }\end{array}$ & BHA Description & $\begin{array}{l}\text { Closest INSPIRE } \\
\text { Elevation Reference } \\
\text { Value }\end{array}$ \\
\hline $\begin{array}{l}\text { 8: "Ground floor height" (the ground has } \\
\text { been substituted for the floor height) }\end{array}$ & AbsHmin & $\begin{array}{l}\text { The absolute minimum height of } \\
\text { the intersection of the external } \\
\text { building walls and the underlying } \\
\text { ground surface }\end{array}$ & Lowest Ground Point \\
\hline $\begin{array}{l}\text { 9: "Height of the base of the building" (can } \\
\text { be above ground for non-obstructing detail, } \\
\text { such as canopies and cantilevered buildings) }\end{array}$ & $\mathrm{AbsH} 1 *$ & $\begin{array}{l}\text { The absolute height of the base of } \\
\text { the building }\end{array}$ & Bottom of Construction \\
\hline $\begin{array}{l}\text { Part of Characteristic 7: "Height of building } \\
\text { to base of roof" }\end{array}$ & $\mathrm{AbsH} 2$ & $\begin{array}{l}\text { The absolute height of the base of } \\
\text { the roof }\end{array}$ & General Eave \\
\hline 6: "Maximum height of roof ridge" & $\mathrm{AbsH} 3 *$ & $\begin{array}{l}\text { The absolute maximum height of } \\
\text { the main roof }\end{array}$ & Top of Construction \\
\hline 5: "Highest point of structure" & AbsHmax & $\begin{array}{l}\text { The absolute height of the highest } \\
\text { point on the building }\end{array}$ & Highest Point \\
\hline $\begin{array}{l}\text { 7: "Height of building to base of roof" } \\
\text { (assuming that the bottom of the building } \\
\text { and the ground are coincident) }\end{array}$ & RelH2 & $\mathrm{AbsH} 2-\mathrm{AbsHmin}$ & $\mathrm{n} / \mathrm{a}$ \\
\hline $\mathrm{n} / \mathrm{a}$ & RelHmax & AbsHmax - AbsHmin & $\mathrm{n} / \mathrm{a}$ \\
\hline
\end{tabular}


The quality assessment of the geometry of building height data is relatively straightforward requiring a comparison of the predicted height to measured values. Additionally, we conjecture that users would be more interested in understanding whether the set of heights meaningfully represents any given building. To this end, we are investigating whether it is possible to flag buildings that can be well represented by an extruded footprint ("simple buildings") and those that cannot ("complex buildings"). This flag can be used for self-diagnoses, to highlight buildings requiring a full 3D model, as well as informing customers of buildings that may deviate from a simple shape. Of course, "well represented" or "simple" are subjective concepts, and so, we defined this using the bottom of roof ( $\mathrm{AbsH} 2)$ position of a building:

A "simple" building is one which has planar vertical walls and for which the base of the most visually-significant roof portion can be well characterised using a single horizontal plane. If such a horizontal plane cannot be easily established, the building will be classified as "complex".

We have found this useful for understanding which buildings are easy to model using a set of heights and those that would be better represented with detailed modelling in three dimensions. Research into this measure continues, and we hope to be able to automatically flag "complex buildings" using point cloud or digital surface model data.

\subsection{Three-Dimensional Shape}

Providing building footprints with building height data is a step towards a 3D building product, but it is clear that some users would prefer a block model for each building. Others would prefer a "full 3D" model in which the roof shape and other aspects of buildings are modelled in 3D. Our original work found that not only is it important to model the shape of the building (Characteristic 3) and the roof (Characteristic 2), but also the space between the buildings (Characteristic 1). The characteristics are particularly important for uses such as analysis of the visual impact of a proposed development, line of sight analysis, access to light modelling and modelling for uses, such as telecommunication network planning and hazard analysis.

Unlike the building height characteristics, which led to building height attributes, these characteristics imply that a 3D model of a building is necessary to meet particular users' needs. To date, most 3D building models have been created by first modelling the roof shape, either by fitting a library roof model (e.g., [24,25]) or by fitting planes (e.g., [26,27]) and merging this solid with an extruded polygon to represent the walls of the building [28]. Other approaches are possible [29], but are not available as off-the-self software options. These roof-focused 3D building models are vital to applications, such as photovoltaic panel positioning [30] and sound propagation modelling (e.g., [31]). However, capturing even these relatively simple 3D models is expensive, requiring a great deal of manual effort. Ordnance Survey has tested a range of software offerings over the years (including SOCET SET, CyberCity Modeller, Erdas Feature Assist, Stereo Analyst and Tridicon [32]), but has yet to identify a method that will cost-effectively populate our database to the required quality. We are supporting further research into this field $[33,34]$.

To further automate 3D building capture and modelling and to provide additional attribution with our building height attributes, we have initiated research into the automatic classification of building roof 
shape. To date, several unsupervised approaches to data analysis have been applied to rotated and scaled roof DSMs. These have identified clusters (using k-means) of building DSMs, including ridged roofs, L-shaped buildings and pyramidal roofs, and appear to have even identified buildings with overhanging vegetation [35]. This approach is in direct contrast to previous roof shape extraction research in that it does not attempt to develop a rule-set or statistical model to label the data, but rather, applies machine learning approaches to "learn" roof classes. We base our approach to this problem on the belief that humans do not label such shapes by, for instance, counting the planes, but by recognition of the pattern that results from the interaction of the planes and curves of the roof.

We have completed several research projects into developing methods for quantifying the geometric fidelity of a model. The research undertaken in partnership with ETH Zurich [36] matched the surface of a 3D city model with a verification point cloud, such as would be obtained using laser scanning. This method allowed us to rapidly identify regions where the 3D model deviated from the "truth". The work focused on using laser scanning from an airborne platform as "ground truth" data to identify discrepancies in the roof model. Methods to quantify such discrepancies have yet to be developed. This should happen following the identification of a suitable 3D data capture method.

Our work looking "below the roof" [37] focused on understanding the shape of the difference between building walls, as modelled using the above "standard" (extrusion) method and the reality as portrayed in ground-based laser scanning. Given a limited sample, the work showed how the assumption of vertical walls spanning from the ground to under the roof can be violated even in quite simple buildings. These two projects have shown how difficult it can be to quantify the quality of the geometric shape of buildings and the space between them.

Further work is required to produce methods for quantifying how well a 3D shape represents reality. For the data producer, research into quality assessment of 3D data is advancing (e.g., [3,5,38]); however, available measures arguably provide little meaning to the user.

In the original 2007 work, probably the most surprising result was the importance of Characteristic 1, the "inter-building geometric shape", specifically for line-of-sight analyses. This characteristic remains the most difficult to adhere to for capture or to identify quality measures. This is largely because the focus of capture methods has been on buildings, and so, the space between those buildings is a much lower priority. In fact, this space is rarely empty, and so, line of sight from one building to another, even if the modelled buildings are perfectly placed, is likely to be interrupted by real-world objects, such as vegetation, street fixtures and vehicles. Clearly, some of these additional features are essential components of 3D spatial data that can be used not only for visualisation, but for analytical purposes. We have undertaken some preliminary research into modelling vegetation in three dimensions. As with buildings, there remain questions about the structure of the model for these data.

\subsection{Attribution Related to Building Geometry}

Whilst the geometry of the whole building appears to be the primary concern of 3D building modelling, there are other attributes of the building that are required for different use cases. Data models, such as the INSPIRE building model [17] and CityGML [18], enable this by allowing the creation from, and decomposition to, component parts of buildings and the attribution of those buildings and 
building parts. As previously stated, we have limited the scope of our work to geometric aspects of building models.

In the original paper, the position and dimensions of windows and doors (Characteristic 4) was found to be of importance to emergency services, those performing flood, crime and security risk analysis and for visual analyses, such as for modelling illumination or for planning purposes. Early results of research into navigational cues [39] indicate that these features are also valuable to pedestrian navigation, especially if located in the lower several meters of a building.

Referring to the CityGML level of detail (LOD) framework [40], our workshop in Loughborough [41] found "Agreement that LOD 0 to 2 can be included in the generic base dataset", and it was "suggested that it could be the responsibility of Ordnance Survey to provide the basic 3D infrastructure, upon which others can build and add more detail". Indeed, such extensibility has been one of the aims of CityGML [42].

As the capture of 3D building models is not yet part of our commercial operation, we are not currently investigating methods for adding features such as windows and doors to 3D models. However, we envisage capturing 3D building data that allow salient features to be incorporated by ourselves, over time, as well as the data user. Towards this vision, we are supporting research into automatically identifying salient features in building textures and assigning semantic information to these $[43,44]$.

Time and again, we have learned how the number of floors (storeys) in a building is of value to customers, such as delivery firms and insurers. It remains to be researched whether we can predict the number of floors of a building with adequate accuracy at an acceptable cost, but this attribute remains something we hope to be able to provide in the future.

In addition to understanding the quality of the "roof geometric shape" (Characteristic 2), we have learned from feedback that many users would be happy with a simple labelling of the building's roof shape class for visualisation activities, such as for planning. The research as described in Section 2.2 into automatically capturing the roof shape class will contribute to providing this attribute.

There are many possible attributes that can enhance 3D building data, but, when it comes to aspects of a building's geometry, the position of windows and doors, the number of storeys and the roof shape are of current priority.

\section{Conclusions}

With such a large investment in processes and infrastructure, national mapping organisations need to get 3D city modelling almost right the first time. We need to be sure that the data we provide are fit for the purpose and that our processes will ensure data of the right quality that can be maintained and developed over the lifetime of the product. We disagree with others (e.g., $[38,45])$ that the onus is with the user to specify what they need in terms of quality. On the contrary, the field of usability and user-centred design has a well-established understanding that "users often do not know what they want or what they need, or even what the possibilities are" [46]. Instead, we have investigated the tasks that different professionals undertake to guide, in the first instance, our view of quality assessment and, later, product design. By focusing on users' tasks, our research has led to the release of DTM and building height data from which a simple city model can be created. As well as developing this into full 3D data, 
we are actively researching the enhancement of our data with attributions that are relevant to the third dimension and methods of flagging the quality of the data that we release. Much remains to be achieved, requiring considerably more data and analysis. Whilst we have established ourselves in a 3D world with building height attributes, being candid, we must admit that we had expected to be further along the route to full 3D geospatial data by now.

We plan to develop our spatial products to include more 3D information, such as supplying ground features as height surfaces and vegetation modelled in 3 dimensions, as well as improved geometric models of buildings. Creating such data at a cost that is acceptable to the customer and that can be easily utilised in existing software is an ongoing focus of our research. We are guided by our knowledge of user requirements, as well as the practicalities of creating products at an acceptable cost. Over the last decade, image matching algorithms have improved considerably, and those available commercially, such as those found in UltraMap 3.0 [47] and SURE [48], are producing extremely detailed and accurate point cloud and digital surface model data. Currently, these sources are under-utilised and, arguably, could provide considerable intelligence (although much is hidden from the user) to the automation of 3D data capture. We expect in the future to be using these data within our processes either using tools that we have developed in-house or, possibly, tools that those software providers are already developing with mapping organisations in mind.

It is noticeable how confidence in 3D geospatial capture and modelling has declined in recent years from comments, such as "Systems for 3-D geospatial data modelling are becoming mature" [47] to something more realistic "3D is a multifaceted and ill-defined problem, and it is unclear whether the benefits of the extra dimension outweigh its complexity" [39]. Still, more and more cities are represented as $3 \mathrm{D}$ city models, and the range of tasks to which these models are being applied is broadening. If these data are to properly serve a range of applications, it is essential that a comprehensive programme of research and development is undertaken to understand and prioritise the needs of users through understanding of their tasks.

\section{Acknowledgements}

Vital to this work were a number of staff from Ordnance Survey: Mark Freeman, who interrogated the task analysis output to extract the 3D building characteristics and contributed to the 3D data quality projects, Dave Capstick (who also created the original Blender ${ }^{\mathrm{TM}}$ models for the figures) and Jon Horgan and Guy Heathcote, who have investigated a range of methods and software products for their contribution to modelling 3D data. The authors are also grateful to our collaborators Kelvin Wong and Claire Ellul, at University College London, Jon Slade, Chris Jones and Paul Rosin, at Cardiff University, and Andrew McClune and Jon Mills, at Newcastle University, for recent discussions and insights about 3D data, data quality and computer vision. We are indebted to the reviewers for their insightful responses to our original submission and the suggestions made for improving this work. We hope that we have done justice to your efforts. 


\section{Author Contributions}

Isabel Sargent conceived of and oversaw the original 3D building characteristics' project, designed the programme of research described in this paper and developed the methods for extracting building height data and roof shape classification. She wrote this paper with substantial input from David Holland and Jenny Harding. Jenny Harding undertook the original user interviews and task analysis, and David Holland advised on all of the projects mentioned and was integral to the recent roof shape and vegetation modelling projects.

\section{Conflicts of Interest}

The authors declare no conflict of interest.

\section{References}

1. Harding, J. Vector data quality: A data provider's perspective. In Fundamentals of Spatial Data Quality; Devillers, R., Jeansoulin, R., Eds.; ISTE: London, UK, 2010; pp. 141-159.

2. Davies, C.; Holt, I.; Green, J.; Harding, J.; Diamond, L. User needs and implications for modelling vague named places. Spat. Cognit. Comput. 2009, 9, 174-194.

3. Schuster, H.F.; Weidner, U. A new approach towards quantitative quality evaluation of 3D building models. In Procedings of the ISPRS Commission IV Joint Workshop Challenges in Geospatial Analysis, Integration and Visualization II, Stuttgart, Germany, 8-9 September 2003.

4. Meidow, J.; Schuster, H.F. Voxel-based quality evaluation of phtogrammetric building acquisitions. In Proceedings of 2005 Object Extraction for 3D City Models, Road Databases and Traffic Monitoring-Concepts, Algorithms and Evaluation, Vienna, Austria, 29-30 August 2005.

5. Landes, T.; Grussenmeyer, P.; Boulaassal, H.; Mohamed, M. Assessment of three-dimensional models derived from lidar and TLS data. Int. Arch. Photogram. Remote Sens. Spat. Inf. Sci. 2012, $34,95-100$.

6. Zeng, C.; Zhao, T.; Wang, J. A multicriteria evaluation method for 3-D building reconstruction. IEEE Geosci. Remote Sens. Lett. 2014, 11, 1619-1623.

7. Musungu, K. Assessing spatial data quality of participatory GIS studies: A case study in Cape Town. In Proceedings of the 2015 Joint International Geoinformation Conference, Kuala Lumpur, Malaysia, 29-30 August 2015; pp. 75-82.

8. Van Erp, J.B.; Cremers, A.H.; Kessens, J.M. Challenges in 3D Geo information and participatory design and decision. In Proceedings of the 5th International Conference on 3D GeoInformation, Berlin, Germany, 3-4 November 2010.

9. De Cubber, I.; Van Orshoven, J. 3D-capabilities required by users of the 2D-large scale topographic reference database in Flanders, Belgium. In Proceedings of the 5th International Conference on 3D GeoInformation, Berlin, Germany, 3-4 November 2010.

10. Stoter, J.E.; Streilein, A.; Pla, M.; Baella, B.; Capstick, D.; Home, R.; Roensdorf, C.; Lagrange, J.P. Approaches of national 3D mapping: Research results and standardisation in practice. In Proceedings of the 8th 3DGeoInfo Conference \& WG II/2 Workshop, Istanbul, Turkey, 27-29 November 2013. 
11. Billen, R.; Cutting-Decelle, A.F.; Marina, O.; de Almeida, J.P.; Caglioni, G.F.; Leduc, T.; Métral, C.; Moreau, G.; Perret, J.; Rabino, G.; et al. 3D City Models and Urban Information: Current Issues And Perspectives. European COST Action TU0801; EDP Sciences: Cedex, France, 2014.

12. Maguire, M. Methods to support human centred design. Int. J. Hum. Comput. Stud. 2001, $55,587-634$.

13. Sargent, I.; Harding, J.; Freeman, M. Data quality in 3D: Gauging quality measures from users' requirements. In Proceedings of the 5th International Symposium on Spatial Data Quality, Santander, Spain, 20-23 June 2007.

14. Morton, P.J. A Global perspective in the development and distribution of VCMs. In Proceedings of the Northumbria Research Conference, Newcastle, UK, 15-16 May 2013.

15. Jazayeri, I.; Rajabifard, A.; Kalantari, M. A geometric and semantic evaluation of 3D data sourcing methods for land and property information. Land Use Policy 2014, 36, 219-230.

16. OS Insight. Available online: http://www.ordnancesurvey.co.uk/business-and-government/helpand-support/os-insight/index.html (accessed on 11 November 2015).

17. INSPIRE Thematic Working Group Buildings. INSPIRE Data Specification on Buildings-Technical Guidelines; European Commission Joint Research Centre: Brussels, Belgium, 2012.

18. Groger, G.; Kolbe, T.H.; Nagel, C.; Hafele, K.H. OGC City Geography Markup Language (CityGML) En-Coding Standard; Open Geospatial Consortium: Wayland, MA, USA, 2012.

19. Nelson, G. We've Launched a New Height Product—OS Terrain 5. Available online: http://www. ordnancesurvey.co.uk/blog/2013/07/weve-launched-a-new-height-product-os-terrain-5/ (accessed on 10 December 2015).

20. Osborne, M. OS OpenData Product Update-OS Terrain 50. Available online: http://www. ordnancesurvey.co.uk/blog/2013/04/os-opendata-product-update-os-terrain-50/ (accessed on 10 December 2015).

21. Nelson, G. New Building Height Data Released. Available online: http://www.ordnancesurvey. co.uk/blog/2014/03/new-building-height-data-released/ (accessed on 10 December 2015).

22. Ordnance Survey. OS MasterMap Topography Layer: User Guide. Avalable online: http://www.ordnancesurvey.co.uk/docs/user-guides/os-mastermap-topography-layer-user-guide.pdf (accessed on 11 November 2015).

23. Amiri Parian, J.; Sargent, I. Automatic height attribute assignment for building polygons: City modeling with level of detail zero. In Proceedings of the 8th Conference on Optical 3-D Measurement Techniques, Athens, Greece, 9-12 July 2007.

24. Huang, H.; Brenner, C.; Sester, M. 3D building roof reconstruction from point clouds via generative models. In Proceedings of the 19th ACM SIGSPATIAL International Conference on Advances in Geographic Information Systems, Chicago, IL, USA, 1-4 November 2011, pp. 16-24.

25. Tseng, Y.H.; Wang, S. Semiautomated building extraction based on CSG model-image fitting. Photogram. Eng. Remote Sens. 2003, 69, 171-180. 
26. Scholze, S.; Moons, T.; Gool, L.V. A probabilistic approach to roof extraction and reconstruction. In Proceedings of the 2002 ISPRS Commision III Symposium, Zurich, Switzerland, 5-7 September 2002; pp. 231-236.

27. Sampath, A.; Shan, J. Segmentation and reconstruction of polyhedral building roofs from aerial lidar point clouds. IEEE Trans. Geosci. Remote Sens. 2010, 48, 1554-1567.

28. Brenner, C. City models-Automation in research and practice. In Photogrammetric Week 01; Wichmann: Hannover, Germany, 2001; pp. 149-158.

29. Musialski, P.; Wonka, P.; Aliaga, D.G.; Wimmer, M.; van Gool, L.; Purgathofer, W. A Survey of urban reconstruction; Comput. Graph. Forum, 2013, 32, 146-177.

30. Wong, K.; Ellul, C. Enhancing positioning of photovoltaic panels using 3D geographic information. In Proceedings of the 21st GIS Research UK (GISRUK) Conference, Liverpool, UK, 3-5 April 2015.

31. Heimann, D. Three-dimensional linearised Euler model simulations of sound propagation in idealised urban situations with wind effects. Appl. Acoust. 2007, 68, 217-237.

32. Capstick, D.; Heathcote, G.; Horgan, J.; Sargent, I. Moving towards 3D: From a national mapping agency perspective. In Proceedings of the 3rd International Conference on the Virtual City and Territory, Bilbao, Spain, 25-27 October 2006.

33. Tse, R.O.C.; Dakowicz, M.; Gold, C.M.; Kidner, D. Building reconstruction using LIDAR data. In Proceedings of the 4th ISPRS Workshop on Dynamic and Multi-dimensional GIS, Pontypridd, UK, 5-8 September 2005; pp. 156-161.

34. McClune, A.P.; Miller, P.E.; Mills, J.P.; Holland, D. Automatic urban 3D building reconstruction from multi-ray photogrammetry. In Proceedings of the ISPRS Technical Commission III Symposium Conference, Zurich, Switzerland, 5-7 September 2014.

35. Sargent, I.M.J.; Holland, D.A. A machine learning approach to roof shape classification. In Proceedings of the 2015 RSPSoc, NCEO and CEOI-ST Joint Annual Conference, Noida, India, 8-11 September 2015.

36. Akca, D.; Freeman, M.; Gruen, A.; Sargent, I. Quality assessment of 3D building data by 3D surface matching. Int. Arch. Photogram. Remote Sens. Spat. Inf. Sci. 2008, 37, 771-778.

37. Freeman, M.; Sargent, I. Quantifying and visualising the uncertainty in 3D building model walls using terrestrial lidar data. In Proceedings of the 2008 Remote Sensing and Photogrammetry Society Conference on Measuring Change in the Earth System, Exeter, UK, 15-17 September 2008.

38. Oude Elberink, S.; Vosselman, G. Quality analysis on 3D building models reconstructed from airborne laser scanning data. ISPRS J. Photogram. Remote Sens. 2011, 66, 157-165.

39. Wong, K.K.Y.; Ellul, C. Designing 3D geographic information for navigation using google glass. In Proceedings of the 23rd GIS Research UK (GISRUK) Conference, Leeds, UK, 15-17 April 2015.

40. Kolbe, T.H.; Gröger, G.; Plümer, L. CityGML-Interoperable access to 3D city models. In Geo-information for Disaster Management, van Oosterom, P., Zlatanova, S., Fendel, E.M., Eds.; Springer: Berlin, Germany, 2005; pp. 883-899.

41. Pretty, S. Your 3D future-How could 3D work for you? Ordnance Survey, Southampton, UK, Unpublished work, 2005. 
42. Kolbe, T.H. Representing and exchanging 3D city models with CityGML. In 3D Geo-Information Sciences; Lee, J., Zlatanova, S., Eds.; Springer: Berlin, Germany, 2009; pp. 15-31.

43. Jones, C.; Rosin, P.; Slade, J. Semantic and geometric enrichment of 3D geo-spatial models with captioned photos and labelled illustrations. In Proceedings of the 25th International Conference on Computational Linguistics, Dublin, Ireland, 23-29 August 2014; pp. 62-67.

44. Slade, J.; Jones, C.B.; Rosin, P.L. Semantic and geometric enrichment of 3D geo-spatial building models with photo captions and illustration labels. In Proceedings of the 23rd GIS Research UK (GISRUK) Conference, Leeds, UK, 15-17 April 2015.

45. Wagner, D.; Alam, N.; Coors, V. Geometric validation of 3D city models based on standardized quality criteria. In Urban and Regional Data Management UDMS Annual; Ellul, C., Zlatanova, S., Rumor, M., Laurini, R., Eds.; CRC Press: Boca Raton, FL, USA, 2013; pp. 197-210.

46. Nielsen, J. Usability Engineering; Morgan Kaufmann: San Francisco, CA, USA, 1994.

47. Wiechert, A.; Gruber, M.; Karner, K.; Ponticelli, M.; Schachinger, B. The power of multi-ray photogrammetry-Ultramap 3.0. In Proceedings of 2012 ASPRS Annual Conference, Sacramento, CA, USA, 19-23 March 2012.

48. Rothermel, M.; Wenzel, K. SURE-Photogrammetric surface reconstruction from imagery; In Proceedings of LC3D Workshop, Berlin, Germany, 6-7 December 2012.

(C) Crown copyright 2015 OS; licensee MDPI, Basel, Switzerland. This article is an open access article distributed under the terms and conditions of the Creative Commons by Attribution (CC-BY) license (http://creativecommons.org/licenses/by/4.0/). 